\title{
Letters
}

\section{The Baltic harbour porpoise and the precautionary principle in conservation: a response to Palmé et al.}

Misunderstanding statistical results in analyses of population structure can jeopardize biodiversity conservation. Consideration of Type I (rejecting a true null hypothesis) and Type II errors (failing to reject a false null hypothesis) in hypothesis testing is crucial. In tests for population structure the null hypothesis is usually that there are no differences between provisional populations, and the threshold for rejection is $\alpha=0.05$. Thus, there is a $1 / 20$ chance of a Type I error. The probability of a Type II error depends on both $\alpha$ and sample size; increasing either reduces the Type II error risk and improves the power to detect population differences. With the Baltic harbour porpoise population being very small (Berggren et al., 2004), the consequence of a Type II error increases the likelihood of extirpation (a non-reversible outcome) and conflicts with the precautionary principle of conservation.

Neither we (Wang \& Berggren, 1997) nor Palmé et al. (2008) presented the two P-values from the Monte Carlo $\chi^{2}$ simulation analysis in REAP v. 4.1 (McElroy et al., 1992): the probability of exceeding the original $\chi^{2}$ by chance, and the probability that includes ties. We (Wang \& Berggren, 1997) believed the correct P-value to report was the former. In retrospect, both P-values should have been presented and discussed. Regardless, the results and conclusion are unaffected.

Our dataset was reanalysed independently using REAP v. 4.1 (Dr Patricia Rosel, National Marine Fisheries Service, USA, pers. comm.) with the following results: the calculated $\chi^{2}$ value was 8.3 (mean $\chi^{2}=6.1$, range 3.9-10.2); $\mathrm{P}=0.034$ \pm SE 0.0018 (341 replicates without ties) and $0.079 \pm$ SE 0.0028 (449 replicates with ties). The slight differences between these values and those in Palmé et al. (2008) and Wang \& Berggren (1997) are probably due to the algorithm's randomization procedure.

The many tied $\chi^{2}$ values are due to the small sample size relative to the population's genetic diversity, and reflect low analytical power for detecting differences. Both P-values represent potential correct values derived from the analyses, with the actual probability in the range $0.034-0.079$, but further resolution requires a larger sample size. Nevertheless, even the higher P-value (0.079) suggests structure. Given low analytical power, this P-value may even be stronger evidence of differentiation than the significant $\mathrm{P}$-value that excludes ties. Furthermore, we argue that any $\mathrm{P}$-value $<0.1$ is grounds for prudent conservative management (i.e. in this case recognizing Baltic porpoises as genetically distinct). Finally, the claim by Palme et al. (2008) of no evidence for genetic distinctness ignored differences in other characters (e.g. craniometry; Börjesson \& Berggren, 1997); population identification is not limited to DNA data (Wang, 2002).

There are also several factual errors in Palmé et al. (2008). One example with serious implications is their erroneous claim of equal migration rates between the sexes. Several studies have shown that females exhibit stronger philopatry than males (Börjesson \& Berggren, 1997; Rosel et al., 1999).

In conclusion, Palme et al. (2008) failed to provide convincing and statistically supported arguments against recognizing a distinct Baltic harbour porpoise population as earlier suggested by us (Wang \& Berggren, 1997).

\section{PER BERGGREN}

Department of Zoology, Stockholm University, SE-106 91

Sweden.E-mail per.berggren@zoologi.su.se

JOHN Y. WANG

FormosaCetus Research and Conservation Group, Canada, and Trent University, Canada.

\section{Acknowledgements}

We thank Doug McElroy, Patricia Rosel, Karen Martien, Barbara Taylor and Brent Murray for constructive comments.

\section{References}

Berggren, P., Hiby, L., Lovell, P. \& Scheidat, M. (2004) Abundance of Harbour Porpoises in the Baltic Sea from Aerial Surveys Conducted in Summer 2002. Paper SC/56/SM7. International Whaling Commission, Cambridge, UK.

BörJESSON, P. \& BERGGREN, P. (1997) Morphometric comparisons of harbour porpoise (Phocoena phocoena) skulls from the Swedish Baltic and Skagerrak Seas. Canadian Journal of Zoology, 75, 280-287.

McElroy, D., Moran, P., Bermingham, E. \& Kornfield, I. (1992) REAP: an integrated environment for the manipulation and phylogenetic analysis of restriction data. Journal of Heredity, 83, 157-158.

Palmé, A., Laikre, L., Utter, F. \& Ryman, N. (2008) Conservation genetics without knowing what to conserve: the case of the Baltic harbour porpoise Phocoena phocoena. Oryx, 42, 305-308.

Rosel, P.E., France, S.C., Wang, J.Y. \& Kocher, T.D. (1999) Genetic structure of harbour porpoise Phocoena phocoena populations in the Northwest Atlantic based on mitochondrial and nuclear markers. Molecular Ecology, 8, 41-54.

WANG, J.Y. (2002) Stock identity. In Encyclopedia of Marine Mammals (eds W.F. Perrin, B. Wursig \& J.G.M. Thewissen), pp. 1189-1192. Academic Press, San Diego, USA.

WANG, J.Y. \& BERGgren, P. (1997) Mitochondrial DNA analysis of harbour porpoises (Phocoena phocoena) in the Baltic Sea, the Kattegat-Skagerrak Seas and off the west coast of Norway. Marine Biology, 127, 531-537. 